\title{
REDD+ policy networks in Indonesia
}

\author{
Moira Moeliono, Levania Santoso and Caleb Gallemore
}

\section{Key points}

1. In Indonesia, Reducing Emissions from Deforestation and Forest Degradation and Enhancing Forest Carbon Stocks (REDD+) has been adopted as a tool to improve forest governance.

2. The promise of more participation and inclusiveness of REDD+ policies has not been fully realized, as information exchange and collaboration occurs mainly within clusters of organizations of similar type (national government, donor agency/international organization/international NGO and domestic NGO).

3. The REDD+ policy arena is populated by a diverse set of actors who agree on basic REDD+ objectives, but differ on implementation and funding mechanisms.

4. As a group, government agencies with a mandate to administer REDD+ are perceived as having the most influence on national REDD+ policy. The Ministry of Forestry (MoF), in particular, is perceived as the most influential organization and therefore has an opportunity to demonstrate transformational change needed for effective REDD+ development and implementation.

\section{Introduction}

Indonesia has adopted and promoted Reducing Emissions from Deforestation and Forest Degradation and Enhancing Forest Carbon Stocks (REDD+) primarily as a tool to improve forest governance, with expected reductions of $\mathrm{CO}_{2}$ emissions a significant co-benefit (Government of Indonesia 2011, Scheyvens and Setyarso 2012). Improving natural resource governance, however, requires changing the course 'not of one ship but of the whole fleet', as one of our interviewees put it. The complexity of forest governance - and the involvement of multiple national and sub-national agencies and interest groups - necessitates that both public and private organizations change existing policies and practices. With the Indonesian government working toward more open policymaking, the national REDD+ strategy was drafted amidst unusually widespread consultations, incorporating input from diverse stakeholders. But who are these stakeholders? Who is involved in national REDD+ policymaking? What are the perceptions, interests and power relations within this policy domain? How do different interactions among policy actors structure the REDD+ policy domain and lead to different policy outcomes?

To answer these questions, CIFOR conducted a study to identify actors involved in the REDD+ policy process, their perceptions on REDD+ and their relationships with one another. Through interviews with actors, we identified the most influential actors, as well as how they are connected through a set of key relationships: information exchange, scientific information exchange, transfers of money and in-kind support, disagreement and collaboration. In this brief, we only discuss two of these relationships: information exchange and collaboration. Additional information was collected through structured and semi-structured interviews concerning perceptions of REDD+ policymaking in the country.

\section{Who is involved in policymaking at the national level?}

The REDD+ policy process coincided with a new openness in government and has consequently involved a considerable number of stakeholders. This study focused on the national level and, with the help of an expert panel, identified 'all organizations perceived by others and that consider themselves having a part in the REDD+ policy domain and thus able to influence (to a bigger or smaller degree) the agenda setting, formulation and implementation of national REDD policies' (Di Gregorio and Brockhaus 2010). We identified 115 policy actors (Table 1). However, due to confidentiality issues and scheduling conflicts, we were only able to interview 68; four of those interviews were incomplete, so only 64 are included in our network analysis. We also realize an organization might have a number of units with different 
Table 1. REDD+ policy actors in Indonesia

\begin{tabular}{|c|c|c|c|}
\hline & $\begin{array}{l}\text { Number } \\
\text { identified }\end{array}$ & $\begin{array}{c}\text { Number } \\
\text { interviewed }\end{array}$ & $\begin{array}{c}\text { Number } \\
\text { included } \\
\text { in network } \\
\text { analysis }\end{array}$ \\
\hline $\begin{array}{l}\text { Central } \\
\text { government } \\
\text { agencies }\end{array}$ & 29 & 17 & 16 \\
\hline $\begin{array}{l}\text { Regional } \\
\text { government } \\
\text { agencies }\end{array}$ & 14 & 3 & 3 \\
\hline $\begin{array}{l}\text { Universities } \\
\text { and national } \\
\text { research centres }\end{array}$ & 8 & 2 & 2 \\
\hline $\begin{array}{l}\text { Private-sector } \\
\text { organisations }\end{array}$ & 16 & 11 & 9 \\
\hline National NGOs & 19 & 13 & 13 \\
\hline $\begin{array}{l}\text { International } \\
\mathrm{NGOs}\end{array}$ & 11 & 10 & 10 \\
\hline $\begin{array}{l}\text { International } \\
\text { organizations }\end{array}$ & 6 & 4 & 3 \\
\hline Donors & 12 & 8 & 8 \\
\hline Total & 115 & 68 & 64 \\
\hline
\end{tabular}

interests and conflicting opinions, though in this study we asked study participants to represent their organisation as a whole.

The Indonesian government assumes the leading role in managing international relations related to REDD+, particularly in collaborating with donor countries such as Norway, as well as translating emerging international standards and expectations for REDD+ into domestic policy. Despite the centrality of the national government in REDD+, not all government agencies are equally engaged, though they tend to agree that REDD+ can and will improve forest governance.

The NGO community concerned with REDD+ can be divided into conservation-oriented and rights-oriented NGOs.

While these two groups oppose each other on many issues, most of the national NGOs agree that REDD+ presents an opportunity to improve governance and, in the process, clarify forest land tenure. They support REDD+, provided it includes social safeguards for local communities. To this end, a group of national NGOs has established an alliance, the Civil Society Forum, which lobbies for the inclusion of social safeguards in national REDD+ policy. Some international conservation NGOs, have included REDD+ as part of their ongoing programs and are undertaking pilot projects in various parts of the archipelago.

Describing the roles and interests of the private sector is somewhat more challenging than it was for the above groups. While informal interviews were granted with some firms, results were confidential. We can, however, divide private sector actors engaged in REDD+ into four categories: those, like palm oil and mining companies, whose activities continue to lead to deforestation and forest degradation, who are pursuing business as usual; green strategists, who have developed environmentally friendly programs as part of corporate social responsibility strategies; carbon money makers, who seek opportunities in the carbon market; and consultants, who provide advice on how to build and work with REDD+.

Research organizations and universities see REDD+ as an exciting new topic for research. As institutions, most are not involved in formal negotiations, although some researchers and academics are involved as individuals. These organizations can provide technical expertise and advice in the development of pilot projects and policies. Local academics, for example, have been particularly active in the development of REDD+ in the pilot province of Central Kalimantan.

\section{Which actors are the most influential?}

REDD+ is seen as involving inclusive, multisectoral and multidisciplinary policy processes. Although state agencies are perceived as the most influential, the Indonesian policy arena is populated by diverse actors. Figure 1 shows the number of times actors are named by other actors as influential in national REDD+ policymaking. It shows that a group of government agencies is considered most influential (see the blue oval in Figure 1). Thus, while there is a trend towards a more open government, multistakeholder consultations and multilevel governance, the government, understandably, is seen as ultimately responsible for public policy decisions.

The Ministry of Forestry (MoF) derives its power by virtue of controlling most forestland, bringing REDD+ under its jurisdiction. Recently, however, its central role in the policy arena has been challenged. Local governments are exerting their autonomy and pressuring the national government to allow conversion of forest to other land uses. In response to a suit brought by four district heads in late 2011, the constitutional court declared that Article 1, Paragraph 3 of the Forestry Law of 1999, defining a forest area as 'designated' rather than gazetted by the Minister of Forestry, is unconstitutional. Although the forest areas delineated in the 1980s are still considered legally valid, most forest areas have not yet been gazetted and therefore can now be easily disputed (Arizona et al. 2012). Local communities, supported by NGOs, have also become more assertive in claiming land.

Nevertheless, the MoF retains formal rights to control forest areas and has issued regulations on the implementation of REDD+. Due to its long-standing procedures, the MoF tends toward a business-as-usual paradigm, reflected in its appropriation of the concession model used for timber extraction for conservation and eco-tourism. REDD+, however, is a new approach requiring changes 


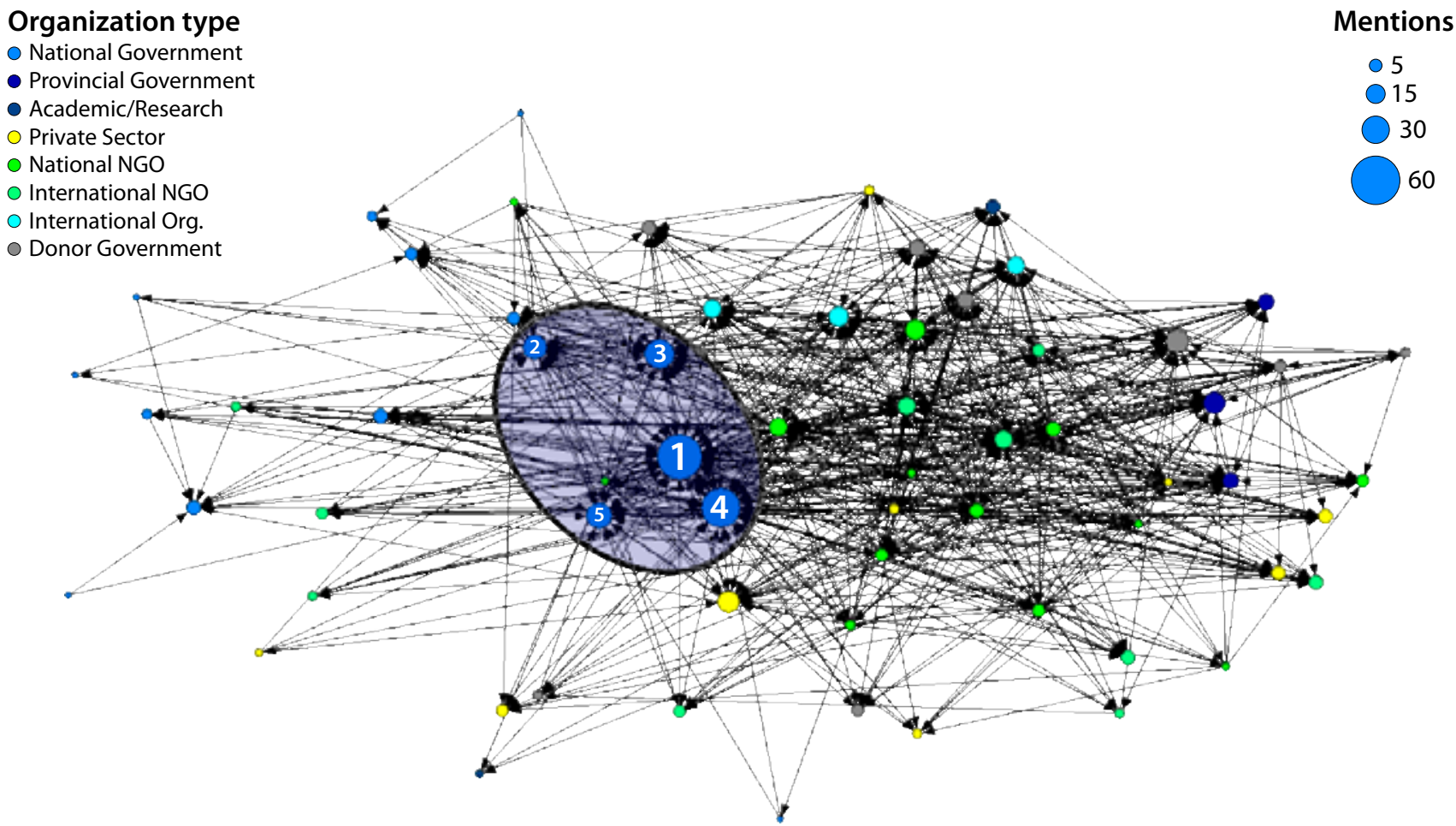

Figure 1. Network of influence. The more often an actor is mentioned as influential, the larger the node size.

Five national government agencies are perceived most influential (highlighted by the oval). Arrows point toward the actor mentioned as influential, away from the respondent organization. Key governmental organizations designated by number: 1=Ministry of Forestry; 2=Ministry of Environment; 3=National Planning Agency; 4=REDD+ Taskforce and $5=$ the National Council for Climate Change.

in attitudes, discourse and power relations, independent of the business-as-usual drivers of deforestation and forest degradation (Brockhaus and Angelsen 2012). The President established the National Council for Climate Change (DNPI) and the Task force on REDD+ to coordinate REDD+ policymaking and implementation, and these institutions clearly also have considerable influence on REDD+ in the country. They are, nevertheless, both outside the formal bureaucracy and therefore cannot operate without the support of more established agencies. As a result of this institutional interdependence, effective REDD+ policymaking in Indonesia requires transparent and accountable cooperation among a diverse group of public and private organizations.

\section{What are the actors' views on REDD+?}

During the survey, we asked respondents to what extent they agreed or disagreed with a set of 35 statements on REDD+. Analysis of the results showed which actors or actor types had similar and dissimilar positions on the issue.

Not surprisingly, government organizations tended to agree with other government organizations, NGOs with other NGOs, and international organizations with other similar organizations, while there was less agreement between NGOs and government. However, while there was overall more agreement within organizations, NGOs tended to have more varied opinions among each other. Overall, respondents had a high level of agreement on the positive aspects of REDD+, for example that REDD+ provides an efficient, affordable and fair scheme to mitigate climate change and provides incentives to improve forest governance. The most significant differences of opinion related to implementation and financing mechanisms. NGOs favoured public funding, while government respondents thought multiple financing mechanisms should be acceptable. Indeed, although many domestic NGOs were sceptical, there was a surprisingly high level of agreement on two statements favouring involvement of the private sector via offset programs or rewarding large-scale industries for lowering emissions. NGOs also felt that financing and accounting could be decentralized, while most government agencies felt it should be administered only by national agencies.

Many respondents were undecided about the feasibility of REDD+ implementation, as indicated by the numbers responding 'neither agree nor disagree' (an average of 20\% on the basic premises of REDD+). Interviews indicated that scepticism increased when the government seemed unable to ensure effective and efficient implementation, while transparency and accountability continued to fall below the expectations of civil society. On the whole, interviewees 
from government and donors, being initiators of the program, were more optimistic that REDD+ could and would be successfully implemented.

The private sector actors we interviewed belonged to only two of the four categories mentioned earlier: green strategists and carbon money makers. Carbon money makers reported successful and ongoing efforts to obtain permits to manage large areas for ecosystem restoration and the generation of carbon offsets. The green strategists included large timber and oil palm companies interested in the potential corporate social responsibility implications of REDD+, who expressed interest in contributing to environmental sustainability and working with local people. One respondent contended, however, that the private sector lacked information and had become aware of the seriousness of climate change only since 2007 when the $13^{\text {th }}$ Conference of Parties of the UN Framework Convention on Climate Change was held in Bali. He suggested that while the private sector is quite willing to get involved in climate change mitigation activities, many actors await more information and leadership from the government.

The survey included several questions on the consultation process to assess the extent of inclusiveness of policy decisions. Most respondents agreed that REDD+ set an example for participatory and inclusive policymaking through public consultations. Nevertheless, there were complaints that there have been too few regional consultations, that not all stakeholders were invited and that there is no evidence of consultations influencing final decisions. While most respondents agree that the policymaking process has been more open to consultations for REDD+ than any previous issues, one noted, 'multistakeholder consultations are excellent for public relations but produce weak concepts', implying inclusiveness came at the price of effectiveness. Indeed, the final strategy was generally considered ineffective as it allows too many compromises and therefore does not sufficiently compel the necessary change from business as usual. In addition, it is non-binding for local government and other land-use based sectoral activities such as mining and plantations.

\section{How do policy actors interact?}

More than any other policy issue in Indonesia, REDD+ raised the interest and facilitated involvement of actors outside the government. This policy arena is populated by many organizations with different interests, agendas and capabilities. Understanding how information is exchanged and how collaboration is structured among the different actors helps identify potential barriers to the transformative change necessary for effective and efficient implementation of REDD+.

\section{Information exchange}

All actors reported exchanging information with others. Figures 2 and 3 map these exchanges. In Figure 2, the size of the nodes indicates the frequency with which an organization was claimed by other actors as an information exchange partner, while in Figure 3 the size of the nodes indicates the number of information partners an organization claims to have.

Figure 2 shows the five government agencies perceived as most influential are also the most claimed by others as exchange partners. The prominence of the MoF (actor 1) might reflect its importance both for information about policy, as well as its considerable information regarding the state of forests in the country. The REDD+ Task Force (2) is equally prominent, likely due to its central role in facilitating stakeholder engagement during drafting of the national strategy. The National Climate Change Council (DNPI) (3) the National Planning Agency (4) and, finally, the Ministry of Environment (5) all have mandates encompassing environmental and climate change concerns.

Figure 3 shows NGOs and donors listing the largest number of other actors as information exchange partners. Two private sector organizations are also shown as actively reaching out to exchange information.

Comparing the two figures shows a clear asymmetry between being nominated as an information partner and nominating others. While this asymmetry might be considered a measure of an organization's perception of its own importance, it does not always indicate that information is not exchanged. Organizations probably recognize exchange of information to different degrees where actors perceived as influential tend only to report major partners in information flow.

Figure 4 shows only those cases where organizations' respondents claimed each other as information exchange partners, in principle indicating stronger relationships. In this visualization, we see a large information exchange cluster consisting of donors, large international conservation agencies and national NGOs. This reflects the alliance promoting awareness of environmental issues that emerged with the environmental movements of the 1980s, which has been renewed around REDD+.

NGO members of the Civil Society Forum form a separate cluster linked to the bigger donors and international NGOs through a 'bridge', with only one organization from each cluster exchanging information directly.

The five government organizations shown earlier to be considered most influential appear as a separate chain, while a fourth cluster consists of two private sector organizations.

A combination of institutional inertia and a tendency of similar organizations to interact more with each other might explain the absence of mutually recognized information exchange between these important groups. The absence of regularized information exchange between groups could limit the potential for REDD+ in Indonesia to evolve into an 


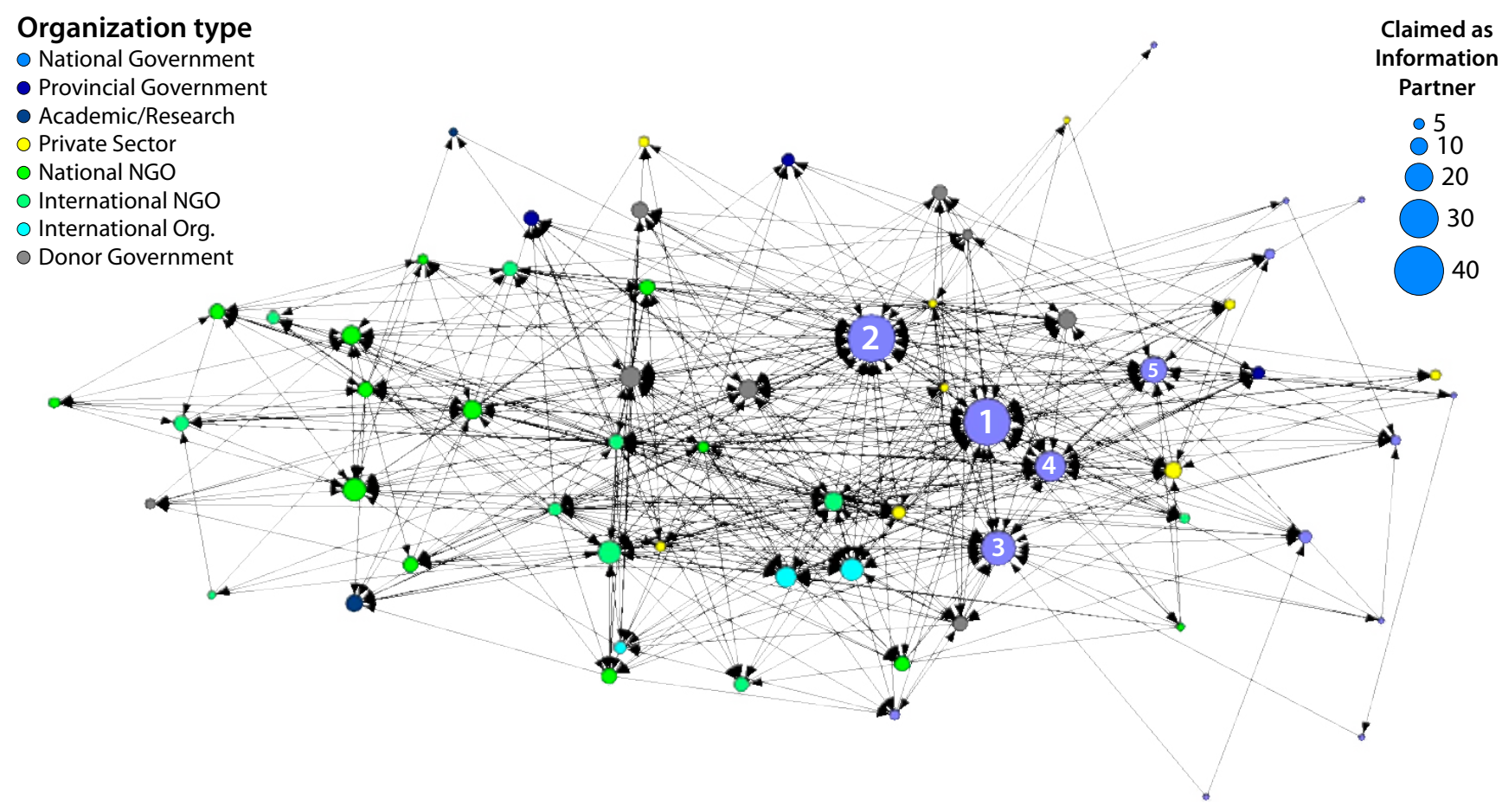

Figure 2. Information network, with organizations more frequently nominated as information exchange partners represented by larger nodes. Arrows point toward the actor nominated as a partner and away from the respondent.

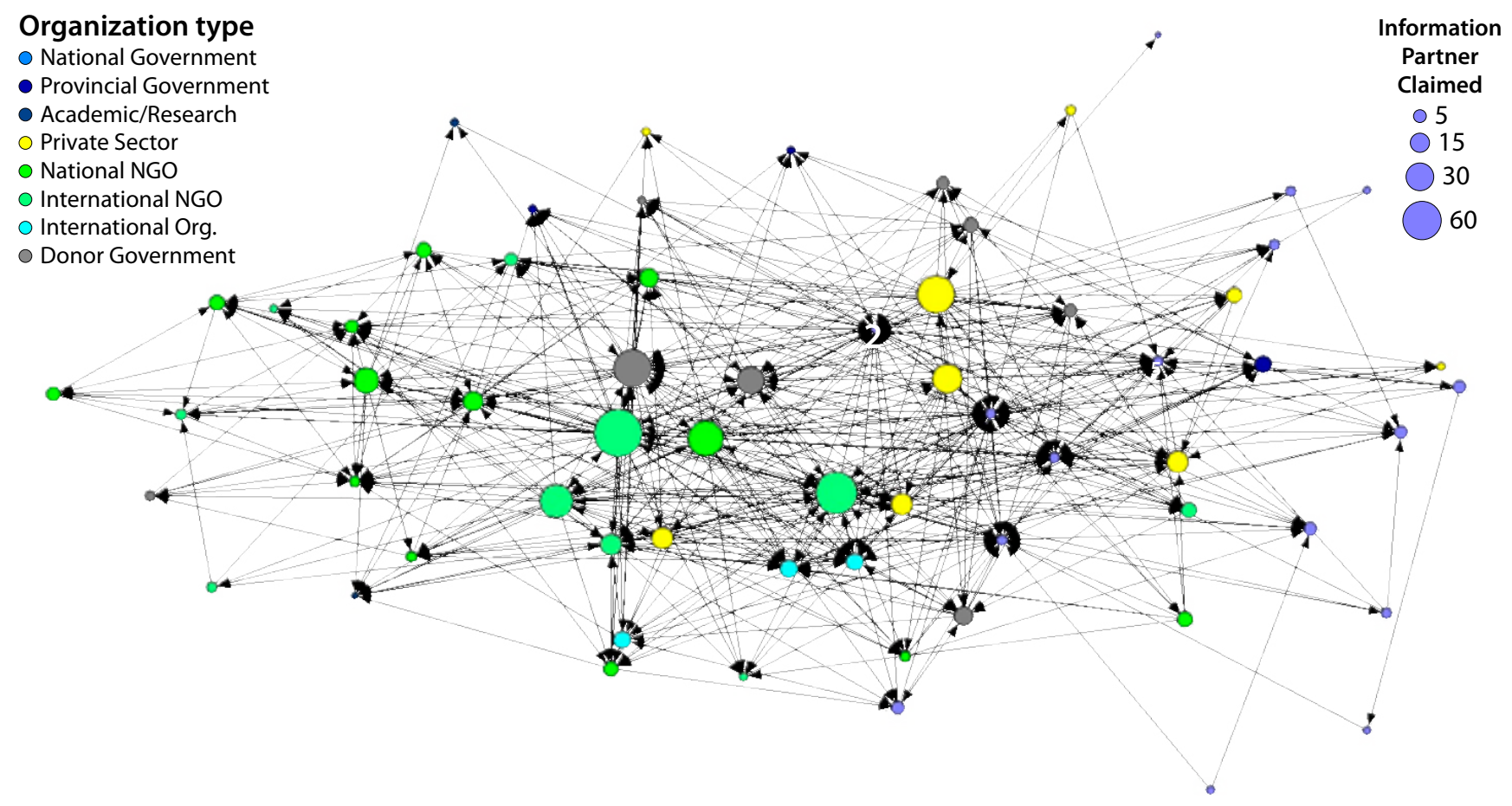

Figure 3. Information network, with organizations that nominated more information exchange partners represented by larger nodes. Arrows point toward the actor nominated as a partner and away from the respondent. 


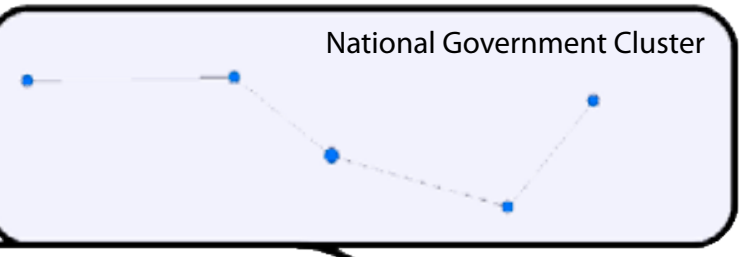

Donor, Transnational and National NGO Cluster

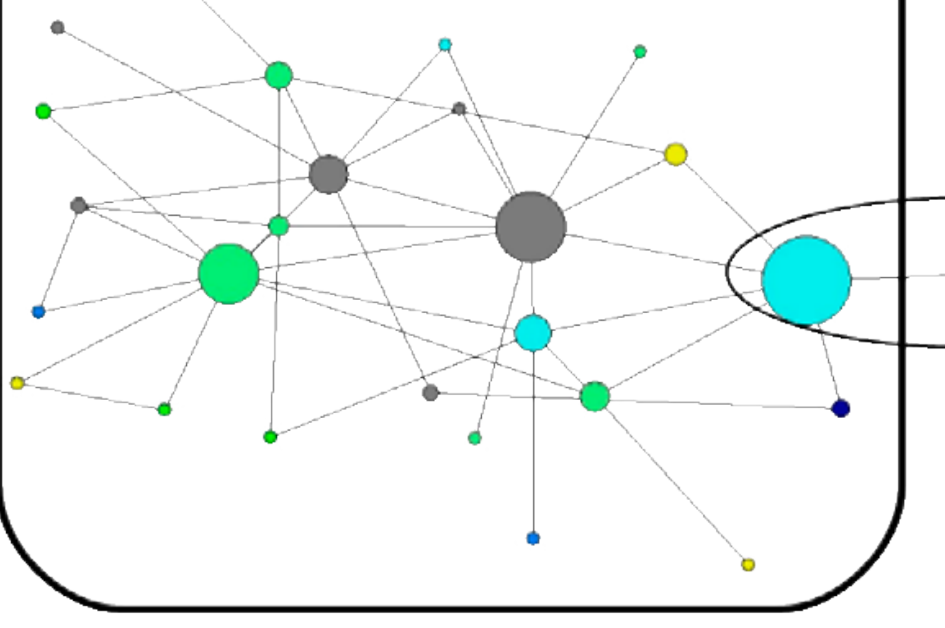

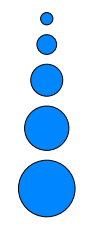

Two Private Sector Organizations

Figure 4. Information network, showing only information exchange relationships reported by both participants.

Node size is scaled by the number of shortest paths between two nodes in the network that pass through each node (betweenness). Only organizations that list one mutually recognized connection are displayed.

effective and participatory governance system, as it indicates a lack of strong communication between major stakeholders and implementing agencies.

\section{Collaboration}

Interviewees also reported on collaboration between their organizations and other actors. Figure 5 shows all collaboration partnerships described by interviewees. All but one organization reported some degree of collaboration, indicating that the complexity of REDD+ necessitates collaboration between different agencies, as well as highlighting the different degrees of involvement in REDD+. Government agencies emerge as important collaboration partners, reflecting their perceived influence.

As with information exchange, only some of the relationships shown in Figure 5 are reported by both partners. Figure 6 shows that mutually recognized collaboration is actually quite rare in our data, mostly confined to similar types of organizations. As with information exchange, this might indicate that organizations tend to recognize relations within the same type more than among types. However, it might also indicate different perceptions on collaboration, where one organization reports collaboration in cases of having received grants or permits which is not seen as collaboration by the grant provider or license issuer.

Not surprisingly, the MoF (1), emerges as the central actor in mutually recognized collaboration among government agencies. As explained earlier, despite emerging challenges, the MoF holds the mandate to administer all forest areas. REDD+ can therefore only be implemented through collaboration or permit from the MoF, which does not necessarily mean that MoF sees an organization as collaborator. Of course, REDD+ cannot be implemented by the MoF alone but requires collaborating with others, but despite this collaboration occurs mostly among same type of organizations.

\section{Conclusion}

REDD+ in Indonesia was adopted as a tool for improving forest governance. The policy process shaping REDD+ promised to be more inclusive, transparent and accountable. While it did include more consultations and information exchange, these were reportedly mostly one-way and top-down. This characterization is supported by our finding that information exchange is still more concentrated within 


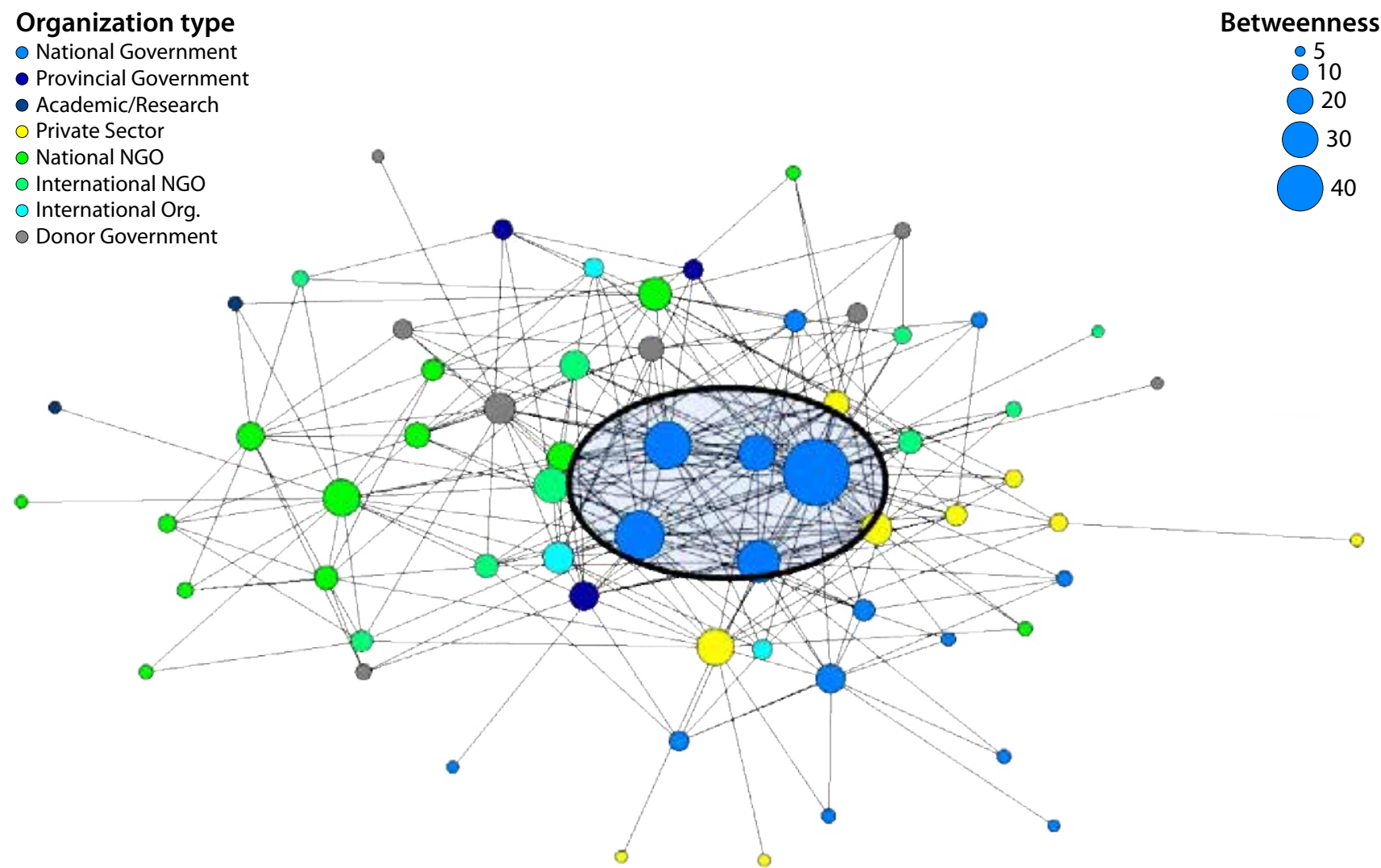

Figure 5. Collaboration network, showing all reported partnerships. Size of nodes denotes the number of reported partners.

organizations rather than among different organizations, and, when interorganizational communication occurs, it occurs most regularly between similar organizations.

The REDD+ policy arena is populated by a multitude of actors, ranging from well-established government agencies such as the MoF to new actors such as carbon investors and consultants. Even within organizations, actors have diverse interests and policy priorities with regard to REDD+, including improving forest governance, promoting better livelihoods for local communities and providing opportunities to make money.

Despite the diversity in the REDD+ policy arena, there is a surprisingly high agreement on many issues. The greatest differences of opinion concern financing. NGOs tend to favour public funding, while other actors would like to see a variety of funding schemes including trust funds as well as private sector investments.

Government agencies which have a mandate to administer REDD+ are perceived as having the most power to influence decisions on national policy, with the MoF being the most influential actor, central in both information exchange and collaboration. Since REDD+ is a forestry issue and the MoF has the legal authority to administer forests, REDD+ is generally perceived as being part of the MoF's mandate. The question is whether the MoF will be able to challenge existing business-as-usual scenarios and realise the transformational change necessary to implement REDD+. Thus far there is little evidence of this. Even schemes intended to conserve forests, such as conservation concessions and eco-tourism initiatives, have to follow rules utilized for timber concessions, a complicated and expensive procedure.

With information exchange and collaboration stronger within organization types than between them, however, the MoF is not the only organization that may have to change its practices. Many actors may be too entrenched within their organizational culture to connect with other actors in a collaborative, transparent and accountable manner.

\section{Acknowledgements}

The research presented here is part of the policy component of CIFOR's global comparative study on REDD (GCS) http:// www.forestsclimatechange.org/global-comparative-studyon-redd.html, led by Maria Brockhaus.

The methods applied in this study build on work undertaken in COMPON ('Comparing Climate Change Policy Networks', http://compon.org/), led by Jeffrey Broadbent and financially supported by the National Science Foundation (NSF). Monica Di Gregorio and Maria Brockhaus adapted the COMPON research 'Protocol for Policy Network Analysis'.

Funding for CIFOR's research was provided by the Norwegian Agency for Development Cooperation, the 


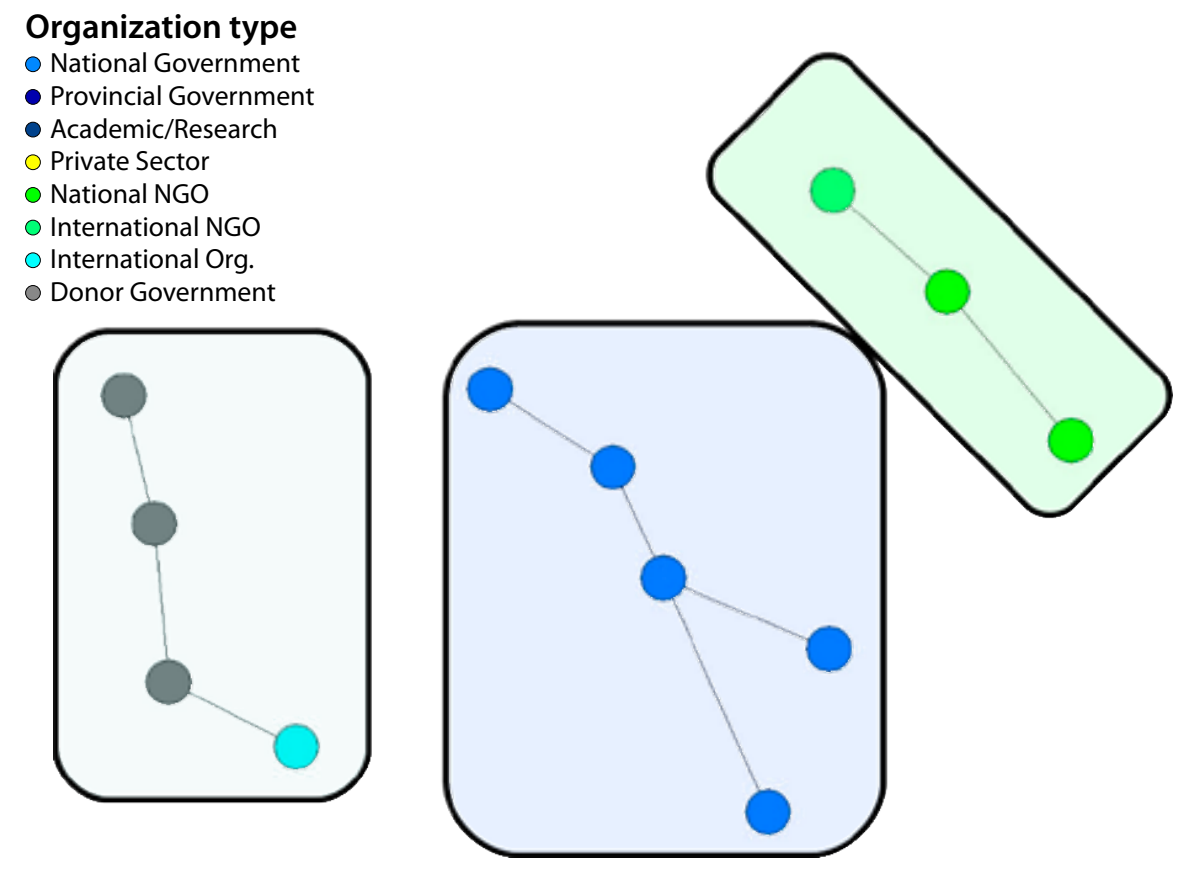

Figure 6. Collaboration network, showing mutually recognized partnerships only.

Australian Agency for International Development, the UK Department for International Development and the European Commission. I would also like to acknowledge the contribution of the reviewers, Monica Di Gregorio and Lou Verchot for their insightful comments and inputs.

\section{References}

Arizona, Y., Herwati, S.R.M and Nagara, G. 2012 Anotasi

Putusan MK no.45/PUU-IX/2011 mengenai pengujian konstitutionalitas pasal 1 angka 3 UU no 41 Tahun 1999 tentang kehutanan. Presentasi pada rapat Pembahasan roadmap forest tenure di Yogjakarta 8-9 Maret 2012.

Brockhaus, M. and Angelsen, A. 2012 Seeing REDD through 4ls: A political economy framework. In: Angelsen, A., Brockhaus, M. Sunderlin, W.D. and
Verchot, L.V. (eds.) Analysing REDD+: Challenges and choices, 15-30. CIFOR, Bogor, Indonesia.

Brockhaus, M. and Di Gregorio, M. 2010 A brief overview: Component 1 on national REDD+ policies and processes. CIFOR Brief 13, June 2012. CIFOR, Bogor, Indonesia.

Government of Indonesia 2011 Final draft of Indonesia's National Strategy on REDD+. http://www.ukp.go.id/ informasi-publik/doc_download/12-draft-final-strateginasional-redd (1 May 2013).

Scheyvens, H. and Setyarso, A. 2012 Development of a National REDD-Plus system in Indonesia. In: Scheyvens, $\mathrm{H}$. (ed.) Developing national REDD-Plus systems: Progress, challenges and ways forward-Indonesia and Vietnam Country Studies, 15-52. IGES, Japan.

This research was carried out by CIFOR as part of the CGIAR Research Program on Forests, Trees and Agroforestry. This collaborative program aims to enhance the management and use of forests, agroforestry and tree genetic resources across the landscape from forests to farms. CIFOR leads the program in partnership with Bioversity International, CIRAD (Centre de coopération internationale en recherche agronomique pour le développement), the International Center for Tropical Agriculture and the World Agroforestry Centre.
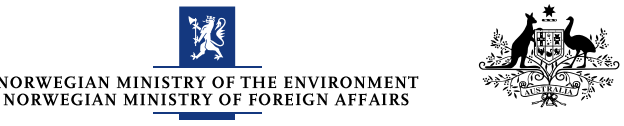

Australian Governmen AusAID

\section{NVI $\nabla \mathrm{AN}$ UKaid}

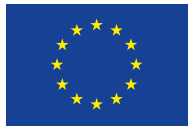

